\title{
ON THE BEST ARRANGEMEN'T OF CITY STREETS.
}

[Contribution from the Department of Civil Engineering, Towne Scientific School, University of Penna.]

\section{By Prof. Lewis M. Haupt.}

It may be safely assumed that facility of communication is one of the most potent elements of human progression and development, hence any obstacle to mobility, however small, becomes a bar to progress, and should, if possible, be removed.

It becomes immediately evident therefore, that the rectangular system of streets is, by itself, defective in consequence of the angles which it opposes to diagonal communications.

Great merit has been awarded $\mathrm{Wm}$. Penn for his prescience in planning this city of Philadelphia, but whilst that plan might answer admirably the requirements of a village, it is very inappropriate to a city of this magnitude. As a matter of history, Penn's letter of instructions to his three commissioners, appointed to execute his designs, will be read with interest.

They were " to seek out a spot on the Delaware River where it is most navigable, high, dry and healthy, where ships may best unload without litering, and where there is good soyle for provisions.

"Having found such a place, lay out ten thousand acres contiguous to it in the best manner you can, as the bounds of said towne; that no more land be laid out until this is taken up; which is the best both - for comfort, safety and traffic.

-Be sure to settle the figure of the towne so as the streets may be uniform down to the river.

"Let the place for the store house be on the middle of the key, which will yet serve for market and state house too, only let the house built be as much upon a line as may be.

"The distance of each house from the creek or harbor sbould be in my judgement a measured quarter of a mile, at least two hundred paces, because of building hereafter streets downward to the harbor.

"Let every house be placed, if the person pleases, in the middle of its platt, as to the breadth way of it so that there may be ground on each side for gardens, orchards or fields, that it may be a greene country towne which will never be burnt, and always be wholesome. "Given at London, Sept. 15, 1681." 
Such was the inception of this, the largest city in area, of the western world. Its growth has far surpassed the most sanguine expectations of its founders, because it combines in its site so many natural advantages. It is readily reached by land or water, its topography is sufficiently undulating to furnish a most perfect system of drainage, with cheap and good water supply, and it has in general a firm and dry soil. Had the original ide of disconnected buildings been adhered to, however, it would always have remained a "greene country towne" of such magnificent distances that but few people could have afforded to live in it. Where would our present population extend to if so domiciled? As concentration and proximity were found to be important elements of defense, intercourse and social and intellectual development, the colonizers soon abandoned the plan and congregated along the river front in both directions until communication became inconvenient, when they began moving along High (now Market) Street towards the Schuylkill.

The rectangular arrangement of streets as proposed being found objectionable, it becomes necessary to examine what other systems, if any, may be used, and determine their relative merits. They may be 1st, regular, or $2 \mathrm{~d}$, irregular, and the first class may be subdivided into rectangular, diagonal and circular; the second into every possible kind of distortion more or less intricate, according to the circumstances attending the growth of a city. All the latter class are discarded as being unscientific, expensive, inconvenient and poorly adapted to the requirements of a growing community.

As people move through a city in every conceivable direction it will be impossible to provide the shortest lines for all, but the case may be met by supposing a greater or less number of centres or points d'appui, to and from which the currents of daily life flow and ebb.

With reference to the subdivisions of the first class it is evident that the straight line being the shortest distance between two points the chord will be shorter than its arc and hence the circular system is defective. The rectangular compels a waste of distance and time and the diagonal by itself becomes the rectangular, so that no single system fulfils all possible requirements. A combination must therefore be resorted to, and that composed of right line elements is both the simplest and most direct. A judicious arrangement of diagonal streets with the rectangular system will doubtless be found to meet more fully than any other, the requirements of the case, but it is 
evident that if the streets be too wide or too numerous the building areas will be correspondingly decreased and a certain proportion of people forced beyond given limits, thus increasing their distances. On the other hand the diagonals will in general open new building lines, with more than residences enough to provide for all the displaced inhabitants.

To illustrate the utility of such a combination, suppose a portion of a town or eity to be laid out in the form of a square whose side is $L$ feet long, and in which the blocks are $l$ feet square and the streets $w$ feet wide.

Let the diagonals of the large square be opened as thoroughfares, and note their effect. The blocks or small squares extend from the middle of one street to that of its parallel, or from the building line of one block to that of the next, hence the length of a side of such square must be $l+w$ (Fig. 1). The area of the small square, including the streets, multiplied by the number of such squares will give the area $L^{2}$ of that portion of the city, and the ratio of street to property area is the same for the small as for the large squares, but the area of the small squares is $(l+w)^{2}=l^{2}+2 l w+w^{2}$ in which $l^{2}$ is the property or building area and $2 l w+w^{2}$ is the street area; the ratio being $\frac{2 l w+w^{2}}{l^{2}}$ and the percentage of street to property area,

$$
\left(\frac{2 l w+w^{2}}{l^{2}}\right) 100 \quad . \quad . \quad . \quad \text {. . . . . . . . }
$$

For any rectangle with streets, of unequal widths, the general formula would be :

$$
\frac{b c+a d+b d}{a c} 100 \text {. . . . . }
$$

in which $a$ and $c$ are the sides of the rectangle, and $b$ and $d$ the widths of the streets. If these quantities are equal, each to each, $A^{1}$ becomes $A$. The number $\left(n^{2}\right)$ of blocks in a given square, whose area is $L^{2}$, will be :

$$
\frac{L^{2}}{(l+w)^{2}}=n^{2}
$$

If now two diagonals, $\overline{M N}$ and $\overline{P Q}$, be introduced, it is evident that where they cross the rectangular streets no additional area is taken from the private property of the city, but they will cut out of 
Haupt-Best Arrangement of City Streets.

$$
\text { Fing } 2
$$
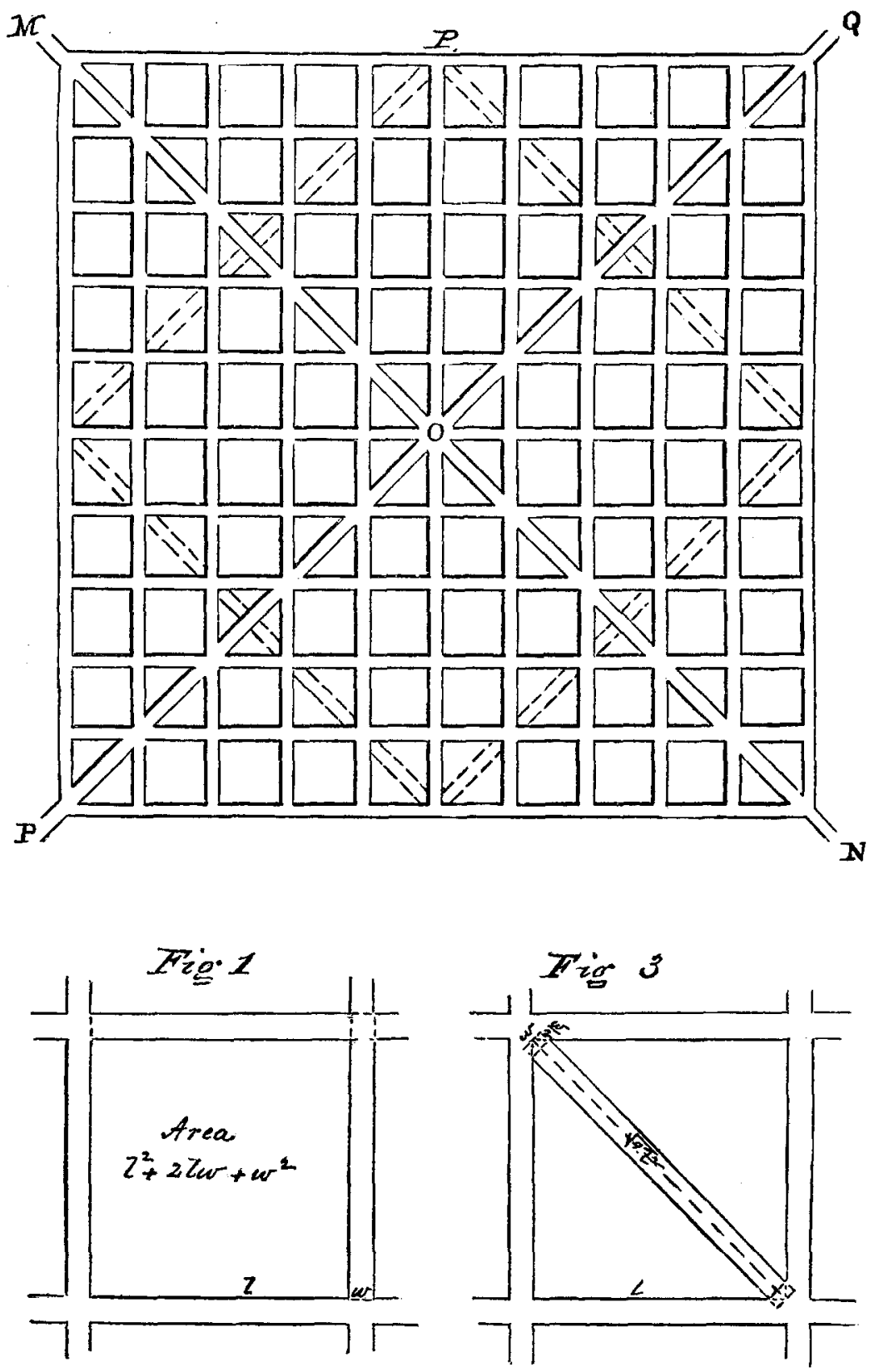
each of the small squares which they cross an area whose length is $\sqrt{2 l^{2}}-\frac{w}{2}$, breadth $w$, and whose area for one block, $l^{2}$, is $\left(\sqrt{2 l^{2}}-\frac{w}{2}\right) w$ (see Fig. 3). For $n$ blocks the total building area consumed from $L^{2}$ by both diagonals, when $n$ is even, will be $2 n w$ $\left(\sqrt{2} l^{2}-\frac{w}{2}\right)$, and the percentage of the building area will be $\frac{2 n w}{n^{2} l^{2}}\left(\sqrt{2 l^{2}}-\frac{w}{2}\right) \times 100$, which reduces to

$$
\frac{w}{n l^{2}}(2 \cdot 828 l-w) 100 \text {. . . . . . . . . . . . . }
$$

the formula for diagonals when $n$ is even. If $n$ be odd, $C$ becomes :

$$
\frac{w}{n l^{2}}(2 \cdot 828 l) 100=282 \cdot 8426 \frac{w}{n l}
$$

If diagonals be opened, benefits will accrue both from the shortening of distance and the additional frontage which will be furnished, while but a small proportion of the inhabitants will be displaced. The greatest economy in distance will be in passing from $M$ to $O$ (Fig. 3), which by the square system is equal to $L$, and by the diagonal $L \sqrt{\frac{1}{2}}$, the ratio being $\frac{L \sqrt{\frac{1}{2}}}{L}=\frac{1.4142}{2}=\frac{70}{100}$, the numerator indicating the distance (in feet) by the diagonals, the denominator by the squares. This gives a gain of 30 per cent., which is the greatest amount possible, and from which it diminishes to zero at $P$.

The total length of frontage on the streets in the square system is $4 l n^{2}$. The diagonals give an additional length of $4 n\left(\sqrt{2 l^{2}}-w\right)$, and the percentage of increase is, therefore:

$$
\frac{l \sqrt{2}-w}{l n} 100 \text {. . . . . . . . . . . . . . . }
$$

The ratio of people displaced is the same as that of the area consumed by diagonals to the entire area $L^{2}$.

To determine these values for any particular case, and so discover whether or not the diagonals will be beneficial, let $l=500 \mathrm{ft}$., $w=$ $50 \mathrm{ft}$., and $n=10$.

Formula (A) gives 21 as the percentage of large or small squares consumed by streets in the rectangular system. 
Formula (C) gives only 2.82 per cent. of additional building area consumed by diagonals.

Formula (D) gives 13 per cent. as the increase in frontage due to diagonals, and it has been shown that the saving of distance varies from 30 per cent. to nothing.

The number of people displaced, which is but 2.82 per cent., will be abundantly provided for by the additional frontage on the diagonals, revenues will be augmented by assessments on the new buildings erected, and a large saving will be effected in time and distance for a majority of the inhabitants by this combination of systems, which is therefore found to fulfil the requirements of practice more fully than any other.

Similar applications of the above formulæ will show to what extent the plans of cities already established or to be built, may be improved by the opening of diagonals, the most economical relation of street to building area, the proper distribution of the street area, and, by extending the analysis, the ratio of pavement to carriage way may also be readily determined. All of these questions have a direct bearing on the convenience, health, and extension of our cities.

St. Gothard Railway.-The estimated cost of this enterprise when it was first undertaken, was $187,000,000 \mathrm{fr}$. It has been found, however, that grave mistakes were made in the original calculations, and M. Hellwag, the present chief engineer, states in his report to the Swiss Government, that an additional capital of at least $102,000,000 \mathrm{fr}$. will be required in order to finish the work. The original estimates were based upon maps on a scale of $1: 10,000$, and did not make sufficient allowance for the protection which would be required against mountain torrents, avalanches, land-slides, falling rocks, and other like contingencies. In consequence of this serious miscalculation the works are suspended, except in the grand tunnel, which has been driven to more than half its length. The decision as to future action is complicated by political questions, arising from the subventions of the German and Italian governments; but the Swiss federal council has appointed a commission of engineers to report upon M. Hellwag's propositions, and it is hoped that satisfactory measures will be devised for carrying them out.Annales des Ponts et Chaussées, Jan., 1877.

C. 